\title{
Application of the natural deep eutectic solvent choline chloride- sorbitol to extract chlorogenic acid and caffeine from green coffee beans (Coffea canephora)
}

\author{
Erline Yuniarti ${ }^{1}$, Fadlina Chany Saputri ${ }^{2}$, Abdul Mun'im $^{3 *}$ \\ ${ }^{1}$ Postgraduate Programe, Faculty of Pharmacy, Universitas Indonesia, Kampus UI Depok, 16424 West Java, Indonesia. \\ ${ }^{2}$ Department of Pharmacology, Faculty of Pharmacy, Universitas Indonesia, Kampus UI Depok, 16424 West Java, Indonesia. \\ ${ }^{3}$ Departement of Pharmacognosy-Phytocemistry, Faculty of Pharmacy, Universitas Indonesia, Kampus UI Depok, 16424 West Java, Indonesia.
}

\begin{tabular}{|c|c|}
\hline ARTICLE INFO & ABSTRACT \\
\hline Received on: 14/09/2018 & \multirow{4}{*}{$\begin{array}{l}\text { This study aimed to determine the optimum method for extracting caffeine and chlorogenic acid (CGA) from green } \\
\text { coffee beans (GCB) of Coffea canephora using choline chloride-sorbitol, a natural deep eutectic solvent (NADES). } \\
\text { Three different preparations of choline chloride-sorbitol and choline chloride-sorbitol-urea }(2: 1,4: 1 \text {, and } 6: 1) \text { were } \\
\text { used for the extraction. The most effective preparation was used to evaluate the effect of dilution with water and } \\
\text { extraction time. Reverse-phase high-performance liquid chromatography, with a gradient solvent system of } 0.1 \% \\
\text { acetic acid }(90 \%) \text { and acetonitrile (10\%), was used to quantify the CGA and caffeine. Choline chloride-sorbitol at } \\
\text { a ratio of } 4: 1 \text { was the most effective for extracting chlorogenic and caffeine, with caffeine and CGA yield of } 4.49 \\
\text { and } 16.59 \mathrm{mg} / \mathrm{g} \text { dry weight, respectively. The optimum water concentration was not found. Using a higher NADES } \\
\text { dilution for extraction corresponded to an increased yield of caffeine and CGA. The effective time for extraction was } \\
\text { found to be } 30 \text { minutes, which yielded the most caffeine and CGA. Based on these results, choline chloride-sorbitol } \\
\text { could be an alternative green solvent for extracting caffeine and CGA from C. canephora GCB. }\end{array}$} \\
\hline $01 / 2019$ & \\
\hline Available online: $30 / 03 / 2019$ & \\
\hline $\begin{array}{l}\text { Key words: } \\
\text { NADES, Coffea canephora, } \\
\text { caffeine, chlorogenic acid, } \\
\text { HPLC. }\end{array}$ & \\
\hline
\end{tabular}

\section{INTRODUCTION}

Coffee is the most popular beverage in the world. It is also one of the main sources of income for many developing countries such as Indonesia (Garg, 2016; Mussatto et al., 2011). Coffea canephora (Mori et al., 2016), synonymous with Coffea robusta (Garg, 2016), is one of the most famous commercial coffee species. Green coffee bean (GCB) refers to unroasted coffee beans and is one form of processed coffee of C. canephora (Garg, 2016). Chlorogenic acid (CGA) and caffeine are the major secondary metabolites in C. canephora seeds (Higdon et al., 2006). CGA is a C. canephora polyphenol and reportedly has pharmacological properties, such as antioxidant (Xu et al., 2012) and lipase inhibition (Mohamed et al., 2014), as well as enhanced glucose and lipid metabolism (Ong et al., 2013). Caffeine has a

\section{"Corresponding Author}

Abdul Mun'im, Department of Pharmacognosy-Phytochemistry, Faculty of Pharmacy, Universitas Indonesia, Depok, Indonesia. E-mail:abdul.munim61@ui.ac.id stimulating effect on the central nervous system (Shimoda et al., 2006), and also acts as a lipase inhibitor (Mohamed et al., 2014).

Currently, green technology is a major priority in chemistry because it is environmentally sustainable and associated with reduced negative effects on humans (Dai et al., 2013a). Natural deep eutectic solvents (NADES) are green solvents (Vian et al., 2017) that completely correspond to green chemistry (Espino et al., 2016). NADES' general components include primary metabolites such as sugars (glucose, fructose, and sucrose), organic acids (lactic, malic, and citric acids), urea, and quaternary ammonium salts such as choline chloride $(\mathrm{ChCl})$ (Dai et al., 2013b). NADES can be used to extract a wide range of metabolites, including polar and non-polar compounds, from plants (Dai et al., 2013a) such as Carthamus tinctorius (Dai et al., 2014), Tartary buckwheat hull (Huang et al., 2017), Sophora japonica (Zhao et al., 2015), and Cajanus cajan (Wei et al., 2015b). The use of ChCl-sucrose as NADES components could increase extraction of phenolic compounds from C. tinctorius by 30 -fold compared to conventional extraction methods (Dai et al., 2014). A NADES consisting of $\mathrm{ChCl}$-glycerine could increase routine extraction from $T$. buckwheat hull by around 


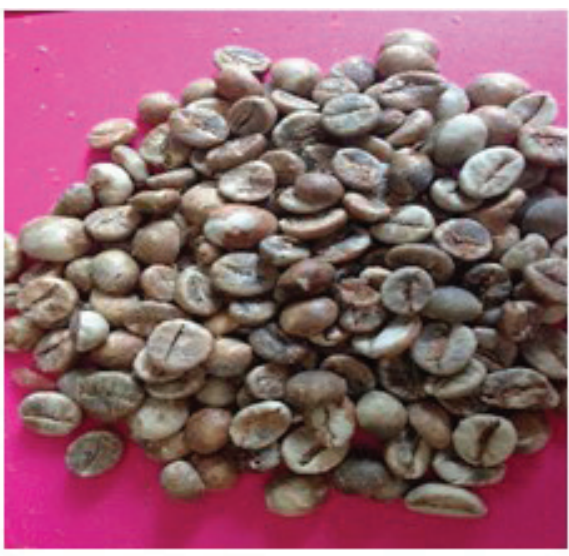

Figure 1. Green coffe bean (GCB).

1,577 times compared to water (Huang et al., 2017). A NADES system, consisting of $\mathrm{ChCl}$ and maltose, influenced extraction of both polar and weak polar phenolic compounds from $C$. cajan leaves (Wei et al., 2015b). Furthermore, ChCl-lactic acid was an excellent extractor of flavonoids (baicalin, wogonoside, baicalein, and wogonin) from Radix Scutellariae (Wei et al., 2015a).

Ahmad et al. (2018) used a high-performance liquid chromatography (HPLC) isocratic system and microplate reader to analyze the caffeine and total polyphenols from Coffea arabica. In this study, caffeine and CGA were simultaneously analyzed using HPLC and a gradient system. There are no reports on using $\mathrm{ChCl}$-sorbitol to extract caffeine and CGA from C. canephora. Therefore, we aimed to identify the optimum extraction conditions for CGA and caffeine from $\mathrm{GCB}$, using $\mathrm{ChCl}$-sorbitol.

\section{MATERIALS AND METHODS}

\section{Plant materials and reagents}

GCB (C. canephora Pierre ex A. Froehner) was obtained from Lampung, Sumatera, Indonesia (Fig. 1). That sample was designated by the Center for Plant Conservation Botanic GardensIndonesian Institute of Sciences [Pusat Konservasi Tumbuhan dan Kebun Raya-Lembaga Ilmu Pengetahuan Indonesia (LIPI)] with number letter B-522/IPH.3/KS/II/2018. The voucher specimen was deposited in the Laboratory of Pharmacognosy and Phytochemistry, Faculty of Pharmacy, Universitas Indonesia. The beans were ground and filtered through sieve No. 40/80. The powders were stored in an airtight bottle and protected from light. Standard CGA [3-caffeoylquinic acid (3-CQA)] was purchased from Osaka City, Wako Pure Chemical Industries (Japan). Standard caffeine was purchased from Shulan City, Jilin Shulan Synthetic Pharmaceutical, China. $\mathrm{ChCl}$ was bought from Xi'an Rongsheng Biotechnology Co., Ltd. (Xi'an, China). Sorbitol powder (Vatican City, Roquette Freres, Frances ) was bought from Jakarta, Barentz, Ltd, Indonesia. All reagents used [methanol (Merck), acetic acid (Merck), and acetonitrile (Merck)] for HPLC were purchased from a local distributor.

\section{Instrumentation}

We used a centrifuge (Heraeus-Christ GmbH, Osterode, Germany), an HPLC system (LC-20AD; Kyoto Shimadzu, Japan) equipped with two pumps (LC-20AD), an autosampler (Sil-20A
HT), an automatic column temperature control oven (CTO-20A), and Inertsil Octadecylsilane (ODS)-3 $5 \mu \mathrm{m}(4.6 \mathrm{~mm} \times 150 \mathrm{~mm}$; Tokyo, GL Sciences Inc, Japan) for the HPLC column.

\section{HPLC-ultraviolet analysis for the simultaneous determination of caffeine and CGA}

The HPLC method was modified from Navarra et al. (2017). There were three mobile phase types, as described below.

Type 1: $0.1 \%$ acetic acid (v/v) (solvent A) and acetonitrile (solvent B). The mobile phase was pumped at $1 \mathrm{ml} /$ minute. The gradient profile ranged from $95 \% \mathrm{~A}$ and $5 \% \mathrm{~B}$ for 20 minutes, then isocratic at $80 \% \mathrm{~A}$ and $20 \% \mathrm{~B}$ for 10 minutes, and back to $95 \% \mathrm{~A}$ and $10 \% \mathrm{~B}$ for 5 minutes. The peak areas were measured at 272 and $326 \mathrm{~nm}$ for caffeine and CGA, respectively.

Type 2: $0.1 \%$ acetic acid (v/v) (solvent A) and acetonitrile (solvent B). The mobile phase was pumped at $1 \mathrm{ml} /$ minute. The gradient profile ranged from $97 \% \mathrm{~A}$ and $3 \% \mathrm{~B}$ for 20 minutes, then isocratic at $80 \% \mathrm{~A}$ and $20 \% \mathrm{~B}$ for 10 minutes, and back to $97 \% \mathrm{~A}$ and $3 \% \mathrm{~B}$ for 5 minutes. The peak areas were measured at 272 and $326 \mathrm{~nm}$ for caffeine and CGA, respectively.

Type 3: $0.1 \%$ acetic acid (v/v) (solvent A) and acetonitrile (solvent B). The mobile phase was pumped at $1 \mathrm{ml} /$ minute. The gradient profile ranged from $90 \% \mathrm{~A}$ and $10 \% \mathrm{~B}$ for 20 minutes, then isocratic at $80 \% \mathrm{~A}$ and $20 \% \mathrm{~B}$ for 10 minutes, and back to $90 \% \mathrm{~A}$ and $20 \% \mathrm{~B}$ for 5 minutes. The peak areas were measured at 272 and $326 \mathrm{~nm}$ for caffeine and CGA, respectively.

The following formula was used to determine CGA and caffeine in the sample:

$$
\text { The concentration sample }=\frac{\text { sample chromatogram area }-a}{b}
$$

where $a$ and $b$ are from the regression linear equation.

$$
\begin{aligned}
\text { Content substances in the sample }= & \text { Concentration sample } \times \\
& \text { dilution factor } \times \text { sample } \\
& \text { volume }
\end{aligned}
$$

The formula to determine the total caffeine and CGA contents in the dry sample is given below:

$$
\text { Total caffeine or CGA Content }=\frac{\begin{array}{l}
\text { amount the Caffeine or } \\
\text { CGA in the extract }(m g)
\end{array}}{\text { GCB sample amount }(g)}
$$

\section{Validation}

Validation was performed by determining the linearity, precision, accuracy, limit of detection (LOD), and limit of quantification (LOQ) for analyzing caffeine and CGA. The method was modified from the Association of Official Analytical Chemist guidelines 2002 .

Linearity was obtained from the calibration curve, which was made by diluting standard stock solutions of caffeine (400 mg/l) and CGA (400 mg/l) with 70\% ethanol, so the concentration range for the calibration curve was $0.4-80 \mathrm{mg} / \mathrm{l}$. The calibration curve was arranged by plotting the area $(y)$ versus the concentration of the standard solution was injected $(x)$ to obtain the linearity equation and the value of $r^{2}$. 


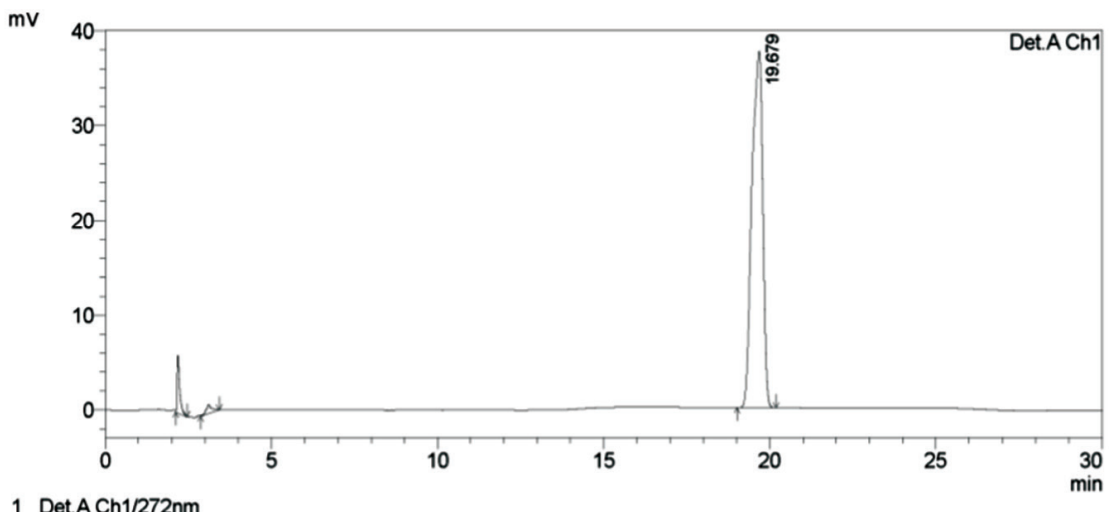

1 Det.ACh1/272nm

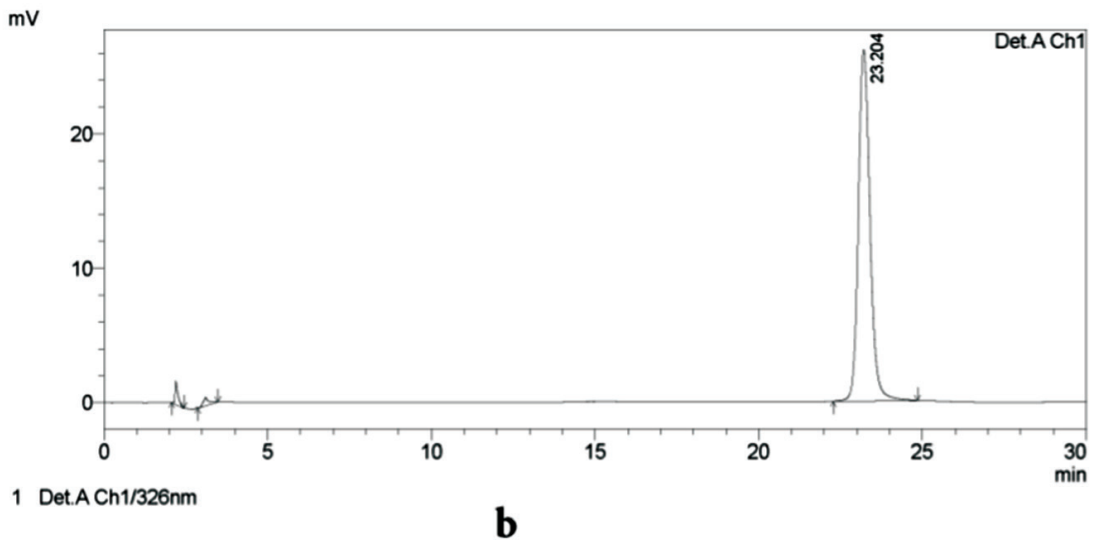

Figure 2. (a) A chromatographic profile with mobile phase type two caffeine and (b) CGA.

Intra-day and inter-day variations were used to obtain precision. Six samples were extracted using NADES $\mathrm{ChCl}-$ sorbitol (4:1) and analyzed under optimized conditions. For the intra-day variation, the samples were analyzed for 2 days, using six samples daily. The precision parameter was: \% Relative standard deviations $(\mathrm{RSD}) \leq 0.67 \times$ Coefficient of Variation $(\mathrm{CV})$ Horwitz.

Recovery was obtained by spiking the sample with standard solutions. Six samples, spiked and un-spiked, were extracted with NADES and analyzed under optimized conditions. As a parameter of accuracy, the recovery range was $97 \%-103 \%$. The LOD and LOQ for caffeine and CGA were obtained by signalto-noise ratios $(\mathrm{S} / \mathrm{N})$ of 3 and 10 , respectively, from six sample spikes.

\section{Composition of NADES}

We used six different NADES compositions: $\mathrm{ChCl}$-sorbitol (2:1), ChCl-sorbitol (4:1), ChCl-sorbitol (6:1), ChCl-sorbitol-urea (2:1:1), ChCl-sorbitol-urea (4:1:1), and ChCl-sorbitol-urea (6:1:1).

\section{Preparation of NADES}

NADES was prepared by heating and stirring. Sorbitol and urea [as a hydrogen bond donor (HBD)] and $\mathrm{ChCl}$ [as a hydrogen bond acceptor (HBA)] were agitated with a magnetic stirrer at $80^{\circ} \mathrm{C}$ until a clear and homogeneous liquid was obtained; this was then diluted with $50 \%$ (v/v) water. Based on the optimum NADES compositions, they were diluted with various volumes of water to obtain concentrations of $25 \%, 50 \%, 75 \%$, and $100 \%$ $(\mathrm{v} / \mathrm{v})$

\section{Extraction procedure}

The extraction procedure was modified from Duan et al. (2016). For all NADES, $1 \mathrm{~g}$ of GCB powder was mixed with $10 \mathrm{ml}$ of the NADES; the mixture was sonicated for 30 minutes and centrifuged at 5,670 $\times g$ for 17 minutes. Furthermore, the suspension was diluted with water for HPLC analysis.

For example, $1 \mathrm{~g} \mathrm{GCB}$ powder was added to $20 \mathrm{ml}$ of ChCl-sorbitol (4:1); the mixture was then sonicated for 15,30 , and 60 minutes, and centrifuged at 5,670 $\times g$ for 17 minutes. The suspension was further diluted with water for HPLC analysis.

\section{RESULTS AND DISCUSSION}

\section{HPLC-ultraviolet analysis for the simultaneous determination of caffeine and CGA}

HPLC has applications and advantages over other compound separation methods in practically all fields of chemistry (Fornstedt et al., 2015; Mc Master, 2007). It is one of the most commonly used methods for quantifying an organic molecule (Moldoveanu and David, 2017), including the secondary metabolite from the plant. Today, HPLC is frequently used to detect multiple compounds simultaneously as it is easier and faster (Fornstedt et al., 2015). For HPLC, using a solvent gradient to modify the separations reached in the column elute 


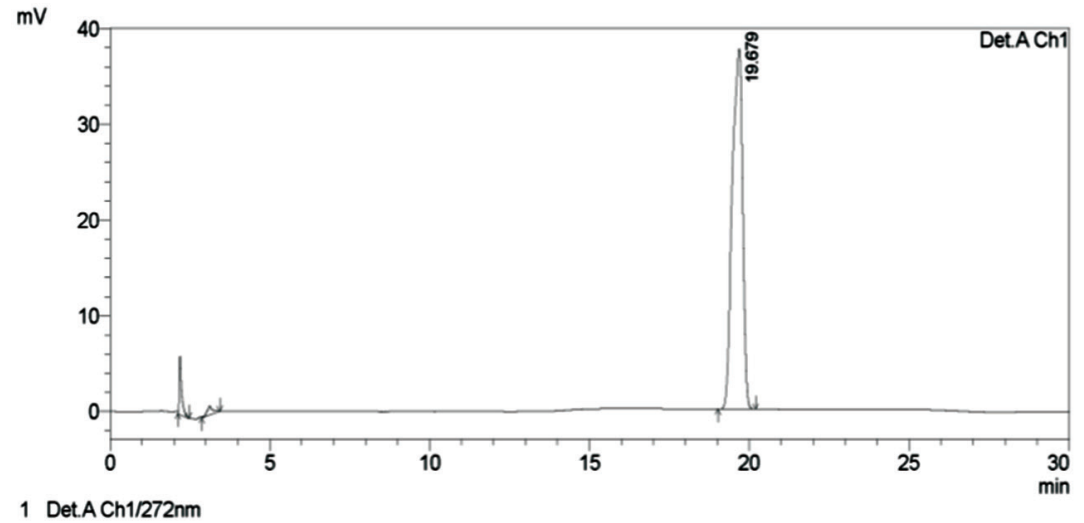

1 Det.ACh1/272nm

$\mathbf{a}$

$\mathrm{mV}$

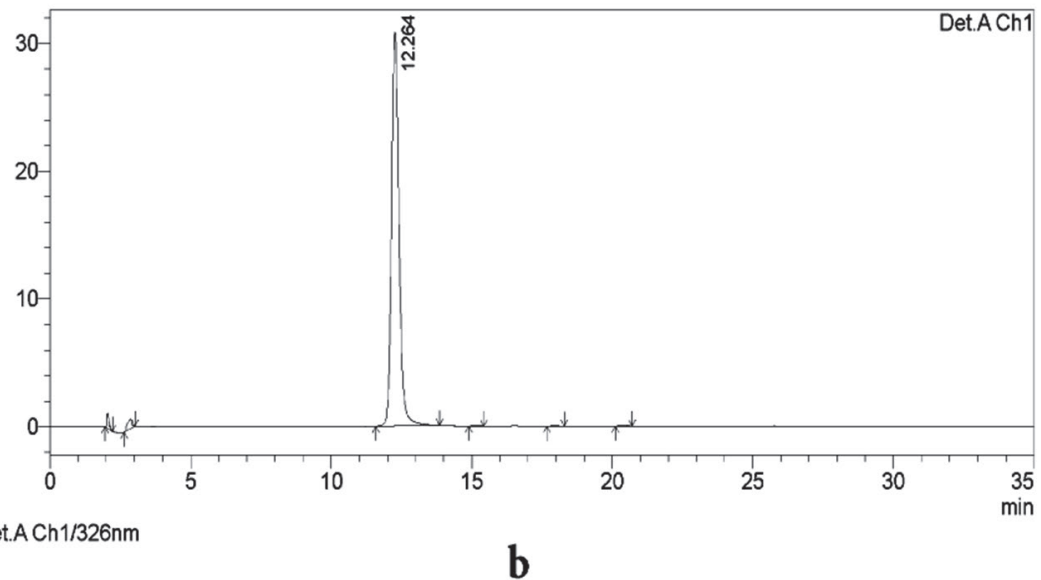

$\mathrm{mV}$

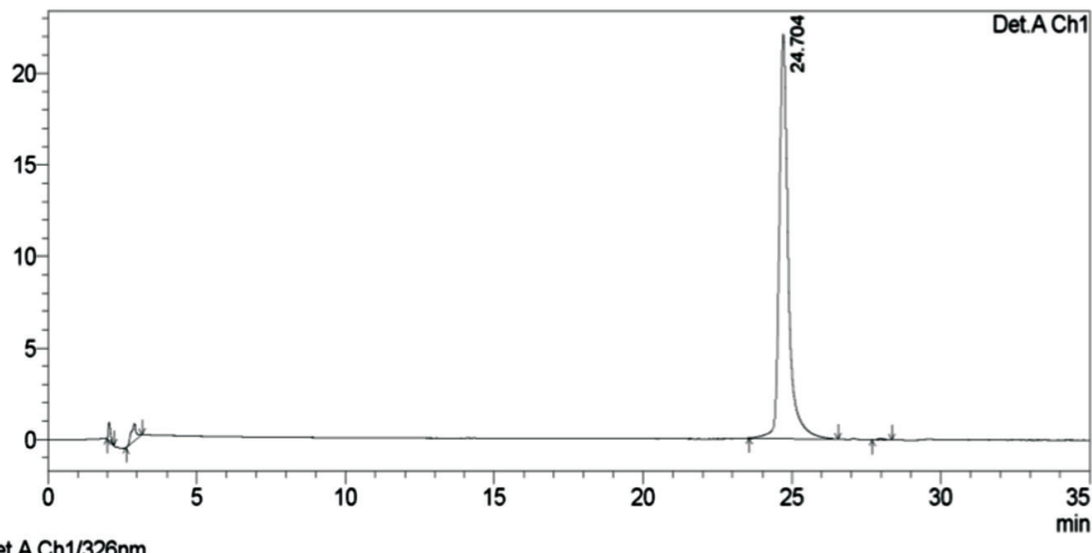

1 Det.ACh1/326nm

b

Figure 3. (a) A chromatographic profile with mobile phase type two caffeine and (b) CGA.

more rapidly because it makes the solvent polarity more like the column polarity. Mobile phases 1, 2, and 3 had different retention times, illustrating that different solvent proportions could affect retention time in the mobile phase (Fornstedt et al., 2015). The caffeine and CGA yields in gradient mobile phase types 1, 2, and 3 were obtained at 19.679 and 23.204 minutes (Fig. 2), at 18.935 and 24.704 minutes (Fig. 3), and at 9.556 and 12.264 minutes (Fig. 4a and b), respectively. Caffeine and CGA were mixed to determine the combined retention time. The acetonitrile concentration was highest in mobile phase 3, leading to briefer retention time. This finding indicates that separation can be achieved by modifying the initial amount of acetonitrile (Mc Master, 2007). We modified mobile phase 3 to simultaneously detect caffeine and CGA by combining the wavelength in one 

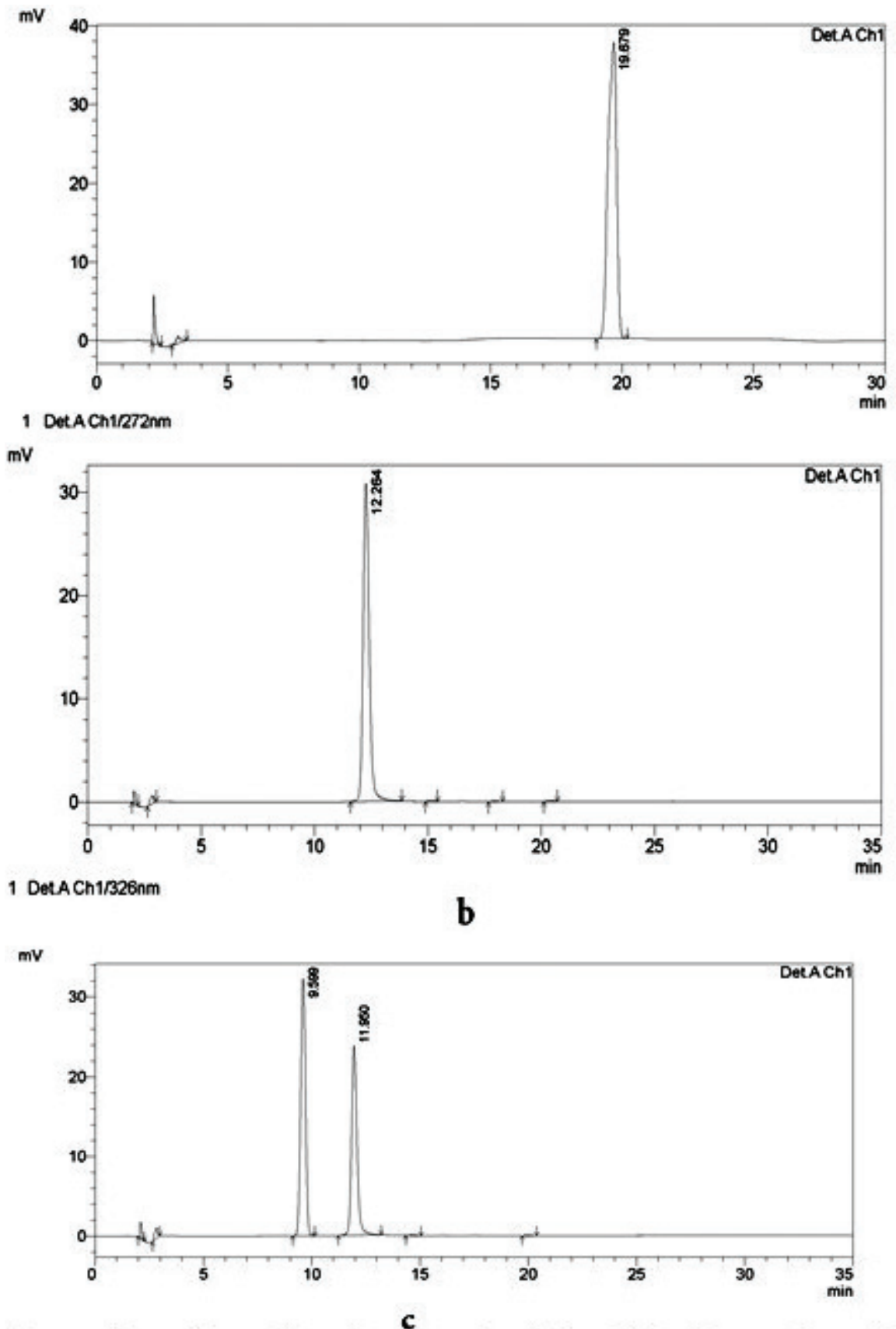

Figure 4. (a) A chromatographic profile with mobile phase type two caffeine, (b) CGA, and (c) the combination form between caffeine and CGA.

liquid chromatography run and setting the wavelength for 272 $\mathrm{nm}$ in 3 minutes and $326 \mathrm{~nm}$ in 11 minutes. The chromatogram of the combination is shown in Figure 4c, with the retention time of 9.599 minutes for caffeine and at 11.950 minutes for CGA. The advantage of this method was using the mobile xphase, which was easier and cheaper than the method used by Navarra et al. (2017)

\section{Validation}

The linear regression equations of the calibration curves for caffeine and CGA (Fig. 5) were $y=79580 \times-24933$ and $y=46057 \times-26606$ and the regression coefficients $(r)$ were 0.99962 and 0.99921 , respectively. The linearity between concentrations and the area with this method were acceptable because the yield of the regression coefficient was more than 0.99 . For intra-day and inter-day, the yield of the precision of CGA and caffeine were summarized in Table 1. RSDs were used to assess the precision. The yield of precision using this method was acceptable because the yield of RSD of CGA and caffeine was less than $0.67 \mathrm{CV}$ Horwitz.

Accuracy was determined by the yield of the recovery. The recovery for caffeine and CGA with this method was shown in 

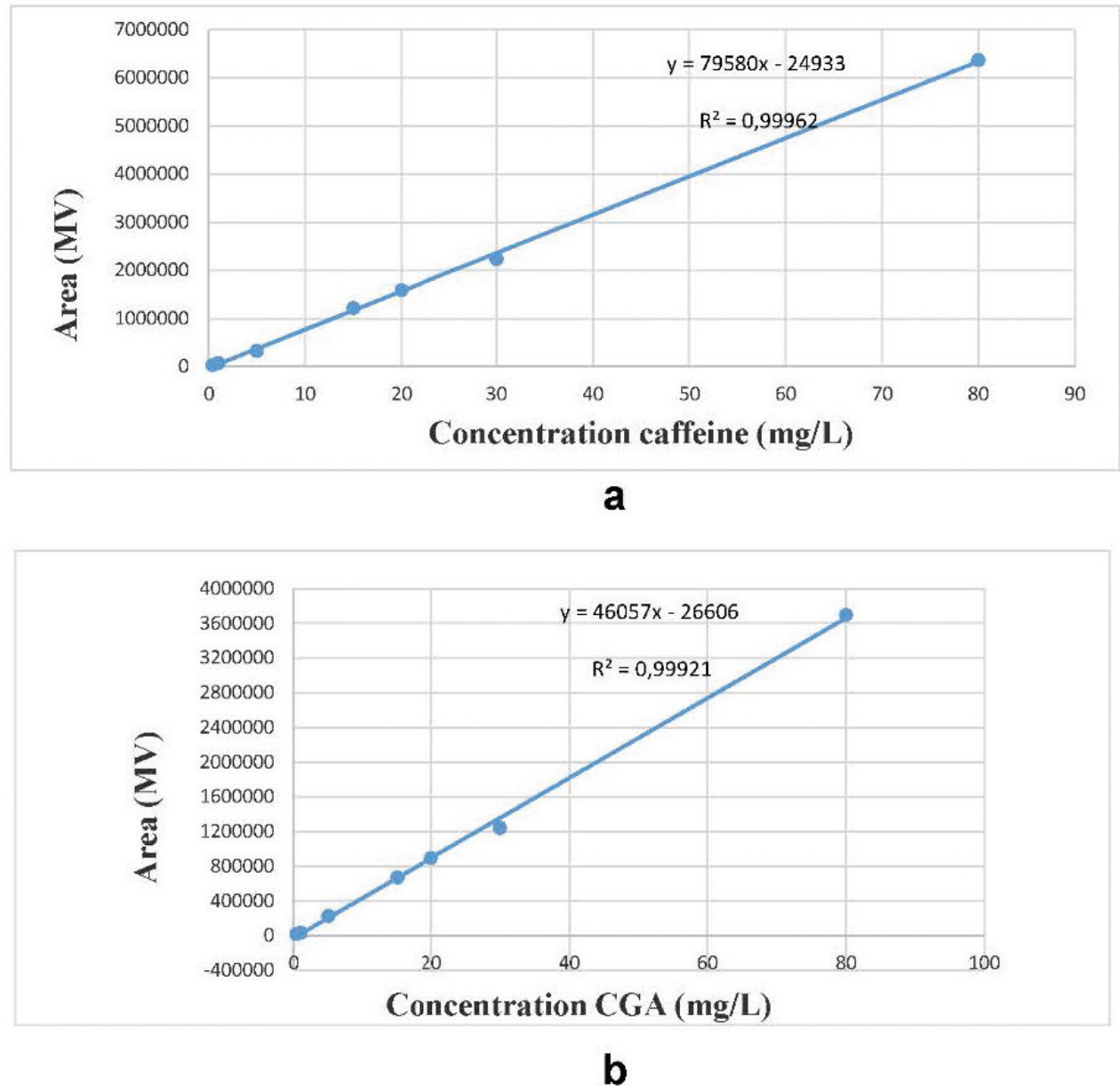

Figure 5. (a) The calibration curve of caffeine and (b) CGA.

Table 1. The yield of precision of CGA and caffeine.

\begin{tabular}{lcccc}
\hline \multirow{2}{*}{ Analyte } & \multicolumn{2}{c}{ Intra-day } & \multicolumn{2}{c}{ Inter-day } \\
\cline { 2 - 5 } & \%RSD & $\mathbf{0 . 6 7}$ CV Horwitz (\%) & \%RSD & $\mathbf{0 . 6 7}$ CV Horwitz (\%) \\
\hline Caffeine & 2.20 & 3.06 & 2.69 & 3.01 \\
CGA & 1.98 & 2.73 & 2.33 & 2.69 \\
\hline
\end{tabular}

Table 2. The yield of recovery of CGA and caffeine.

\begin{tabular}{lcc}
\hline \multicolumn{1}{c}{ Analyte } & Amount of spike $(\boldsymbol{\mu g} / \mathrm{ml})$ & Recovery $(\%)$ \\
\hline Caffeine & 2,000 & 98.58 \\
CGA & 1,000 & 100.2 \\
\hline
\end{tabular}

Table 3. The result of LOD and LOQ of caffeine and CGA.

\begin{tabular}{lcc}
\hline \multicolumn{1}{c}{ Analyte } & LOD $(\boldsymbol{\mu g} / \mathbf{g})$ & LOQ $(\boldsymbol{\mu g} / \mathbf{g})$ \\
\hline Caffeine & 12.79 & 42.62 \\
CGA & 27.95 & 93.15 \\
\hline
\end{tabular}

Table 2. The yields of recovery using this method were acceptable because they were in the range of $97 \%-103 \%$. LOD and LOQ were shown in Table 3.

\section{The composition of NADES and extraction procedure}

In this study, green chemistry was used to improve the extraction process and obtain the optimum yield of caffeine and CGA from GCB. The extraction method was described in Duan et al. (2016). Ultrasound-assisted extraction (UAE) was used because it is usually simple, effective, fast, and applicable to any type of solvent (Nam et al., 2015). In this evaluation, we modified mobile phase type 3 because the range of separation and retention time for caffeine and CGA is briefer than that of the other mobile phases. Figure 6 illustrates the result of the CGA and caffeine concentrations in various NADES compositions. The composition of $\mathrm{ChCl}$-sorbitol that could effectively extract CGA and caffeine was in the ratio 4:1; the yield of caffeine and CGA were 4.49, and $16.59 \mathrm{mg} / \mathrm{g}$ dry powder. The extract's density was $1.067 \mathrm{~g} / \mathrm{ml}$. The density and the amount of CGA and caffeine in the extract could be an extract quality parameter (Garg et al., 2012). This extraction with NADES did not need to be dried and, therefore, could be used immediately.

Based on the data shown in Figure 6, both ChCl:sorbitol:urea and $\mathrm{ChCl}$ :sorbitol could be used to extract caffeine and CGA in HPLC. This finding proved that NADES can extract metabolite compounds in the plant (Dai et al., 2013a) and can be used as a solvent (Espino et 


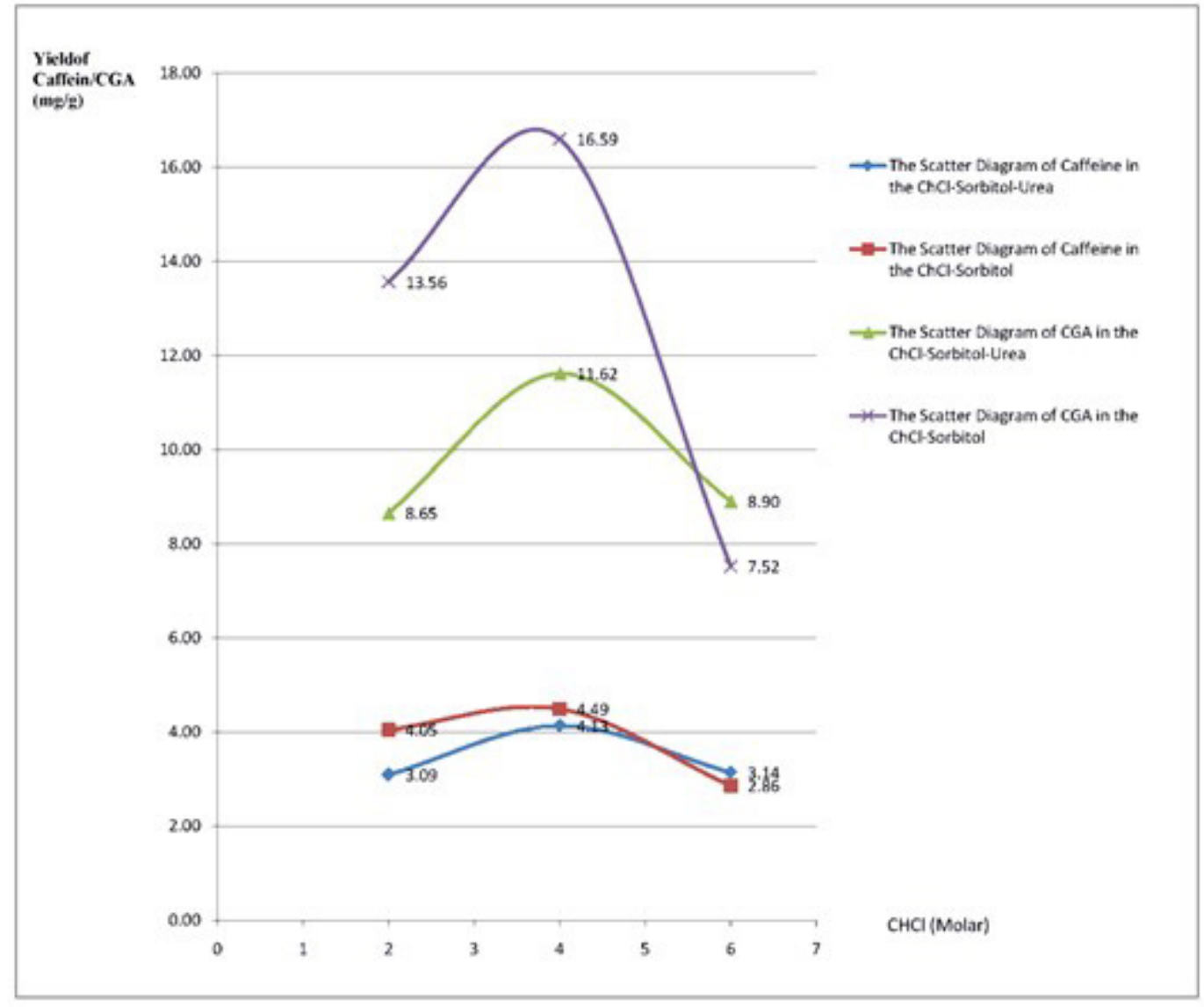

Figure 6. The scatter diagram for caffeine and CGA in NADES choline chloride-sorbitol-urea (ChCl:S:U) and choline chloride-sorbitol (ChCl:S).

Table 4. The yield of CGA and caffeine in the variation of dilution.

\begin{tabular}{cccc}
\hline No & Dilution (\%,v/v) & Caffeine(mg/g) & CGA(mg/g) \\
\hline 1 & 25 & 1.87 & 4.89 \\
2 & 50 & 4.22 & 14.53 \\
3 & 75 & 6.40 & 20.79 \\
4 & 100 & 8.63 & 28.70 \\
\hline
\end{tabular}

Table 5. The yield of CGA and caffeine in the variation time.

\begin{tabular}{cccc}
\hline No & Time (minutes) & Caffeine(mg/g) & CGA(mg/g) \\
\hline 1 & 15 & 3.90 & 9.87 \\
2 & 30 & 4.57 & 11.53 \\
3 & 60 & 3.64 & 8.39 \\
\hline
\end{tabular}

al., 2016). The other advantages of using NADES are biodegradability (Dai et al., 2014), non-toxicity (Dai et al., 2014), and designer solvent (Espino et al., 2016), that is, with adjustable viscosity (Vian et al., 2017). $\mathrm{ChCl}$ :sorbitol:urea (4:1:1) and $\mathrm{ChCl}$ :sorbitol (4:1) provided the optimum yield for caffeine. To obtain the optimum dilution and extraction times, we used $\mathrm{ChCl}$ :sorbitol (4:1) as it had higher caffeine and CGA yields than ChCl:sorbitol:urea (4:1:1). Thus, different NADES compositions could extract solutes with different properties due to their different physicochemical properties, such as H-bonding interactions and polarity (Faggian et al., 2016). NADES occurs by mixing solid chemicals (Dai et al., 2013b) to form a eutectic system, and the hydrogen bonds and van der Waals interactions form a driving force in this system (Espino et al., 2016). Urea and sorbitol serve as the $\mathrm{HBD}$, and $\mathrm{ChCl}$ acts as the $\mathrm{HBA}$; therefore, both $\mathrm{H}$ bonds and van der Waals forces form the eutectic system. $\mathrm{ChCl}$ is a natural product forming a liquid from any primary metabolite (Dai et al., 2013a). The liquid formed between $\mathrm{ChCl}$ and sorbitol remains stable in the liquid state for over 7 days because the chloride ion from $\mathrm{ChCl}$ can bond with two hydrogen bonds and two hydroxyl groups from sorbitol; moreover, their spatial structure has a strong effect on hydrogen bond stability (Dai et al., 2013a).

Table 4 shows the caffeine and CGA yields when extracted using various dilutions of ChCl-sorbitol (4:1). Table 5 shows the effects of different extraction times.

Based on Table 4, using a higher NADES dilution for extraction corresponded to an increased yield of caffeine and CGA. NADES are large molecules with hydrogen bonds. The interactions are destabilized when water is added, and they will disappear if the water percentage exceeds $50 \%(\mathrm{v} / \mathrm{v})$ (Dai et al., 2015). The impact of dilution on NADES could serve as a foundation to develop custom NADES for different applications, such as the dissolution of compounds, and have great potential for various uses in pharmaceuticals, foods, and cosmetics (Dai et al., 2015). 


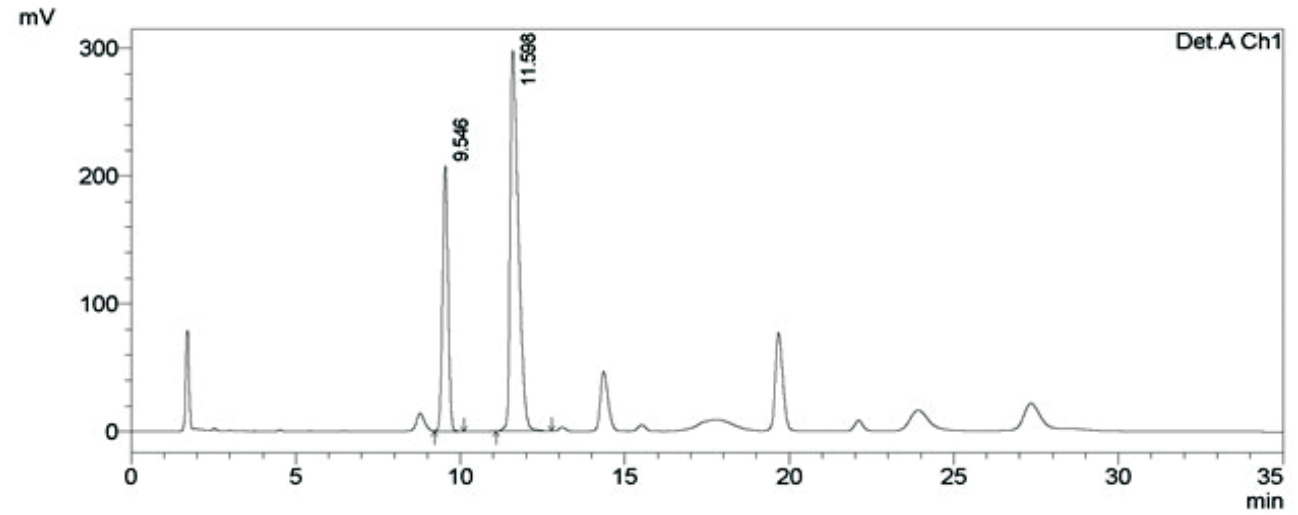

Figure 7. A chromatographic profile of caffeine and CGA in the sample.

Table 5 shows the results of CGA and caffeine concentrations with different extraction times. The optimum extraction time was found to be 30 minutes; at that point, the caffeine and CGA yields were the highest at 4.57 and $11.53 \mathrm{mg} / \mathrm{g}$ dry powder, respectively. These results together could form the basis for further research to optimize a ChCl-sorbitol-based UAE method by response surface methodology, with several extraction conditions, to maximize the yield of the target compound from $C$. canephora. On contrary, the future works of the extract with that NADES could be developed as a raw material for nutraceuticals and the pharmaceuticals.

Figure 7 illustrates a chromatogram of caffeine and CGA separated using $\mathrm{ChCl}$ :sorbitol (4:1). The retention times of caffeine and CGA were 9.610 and 11.908 minutes. Based on Jeon et al. (2017), the CGA isomers after 3-CQA are 4-CQA and 5-CQA. This also proves that NADES can extract a wide range of metabolites from the plant (Dai et al., 2013a).

\section{CONCLUSION}

This work revealed that the modified mobile phase type 3 could be used to simultaneously determine the caffeine and CGA, using HPLC, because the retention times of both caffeine and CGA are shorter than the other types; furthermore, caffeine and CGA can be separated properly with this system.

The effective composition of ChCl-sorbitol that could extract CGA and caffeine was $4: 1$. When this ratio was used, the caffeine and CGA yields were 4.49 and $16.59 \mathrm{mg} / \mathrm{g}$ dry powder, respectively. This result proves that NADES can extract metabolite compounds in the seeds. Therefore, $\mathrm{ChCl}$-sorbitol can be used as an alternative green solvent to extract caffeine and CGA in $C$. canephora GCB.

\section{ACKNOWLEDGMENTS}

This work was financed by Universitas Indonesia via Hibah Publikasi Internasional Terindeks untuk Tugas Akhir 2018. The National Quality Control Laboratory of Drugs and FoodNational Agency of Drug and Food Control provided the HPLC instrument.

\section{CONFLICT OF INTEREST}

All authors stated that there are no conflicts of interest.

\author{
ABBREVIATIONS \\ CGA: chlorogenic acid; \\ 3-CQA: 3-caffeoylquinic acid; \\ $\mathrm{ChCl}$ : choline chloride; \\ GCB: green coffee beans; \\ HPLC: high-performance liquid chromatography; \\ NADES: natural deep eutectic solvents; \\ S: sorbitol; \\ U: urea.
}

\section{REFERENCES}

Ahmad I, Pertiwi AS, Kembaren YH, Rahman A, Mun'im A. Application of natural deep eutectic solvent-based ultrasonic-assisted extraction of total polyphenolic and caffeine content from coffee beans (Coffea Beans L) for instant food products. J Appl Pharm Sci, 2018; 8: $138-43$.

Dai Y, Spronsen JV, Witkamp G. Natural deep eutectic solvents as new potential media for green technology. Analytica Chimica Acta, 2013a; 766:61-8

Dai Y, Van SJ, Witkamp GJ, Verpoorte R, Choi YH. Ionic liquids and deep eutectic solvents in natural products research: mixtures of solids as extraction solvents. J Nat Prod, 2013b; 76:2162-73.

Dai Y, Verpoorte R, Choi YH. Natural deep eutectic solvents providing enhanced stability of natural colorants from safflower (Carthamus tinctorius). Food Chem, 2014; 159:116-21.

Dai Y, Witkamp GJ, Verpoorte R, Choi YH. Tailoring properties of natural deep eutectic solvents with water to facilitate their applications. Food Chem, 2015; 187:14-9.

Duan L, Dou LL, Guo L, Li P, Liu EH. Comprehensive evaluation of deep eutectic solvents in extraction of bioactive natural products. ACS Sustain Chem Eng, 2016; 4:2405-11.

Espino M, De Los Ángeles Fernández M, Gomez FJV, Silva MF. Natural designer solvents for greening analytical chemistry. Trends Anal Chem, 2016; 76:126-36.

Faggian M, Sut S, Perissutti B, Baldan V, Grabnar I, Dall'Acqua S. Natural deep eutectic solvents (NADES) as a tool for bioavailability improvement: pharmacokinetics of rutin dissolved in proline/glycine after oral administration in rats: possible application in nutraceuticals. Molecules, 2016; 21:1-11.

Fornstedt T, Forssén P, Westerlund D. Basic HPLC theory and definitions: retention, thermodynamics, selectivity, zone spreading, kinetics, and resolution. Anal Separat Sci, 2015; 5:1-24.

Garg SK. Green coffee bean. Nutraceuticals, 2016; 4:653-67. 
Garg V, Dhar VJ, Sharma A, Dutt R. Facts about standardization of herbal medicine: a review. J Chinese Integr Med, 2012; 10:1077-83.

Higdon JV, Frei B. Coffee and health: a review of recent human research. Crit Rev Food Sci Nutr, 2006; 46:101-23.

Huang Y, Feng F, Jiang J, Qiao Y, Wu T, Voglmeir J, Chen ZG. Green and efficient extraction of rutin from Tartary buckwheat hull by using natural deep eutectic solvents. Food Chem, 2017; 221:1400-5.

Jeon J, Kim H, Jeong I, Hong S, Oh M. Determination of chlorogenic acids and caffeine in homemade brewed coffee prepared under various conditions. J Chromatogr B, 2017; 1064:115-23.

Mc Master M. HPLC a practical user's guide (2nd Ed). A John Wiley \& Sons, Inc, Hudson, 2007.

Mohamed GA, Ibrahim SRM, Elkhayat ES, El Dine RS. Natural anti-obesity agents. Bull Faculty Pharm Cairo Univ, 2014; 52:269-84.

Moldoveanu SC, David V. Start of the implementation of a new HPLC method. In: Selection of the HPLC method in chemical analysis, Elsevier Inc, Netherlands, pp 1-29, 2017.

Mori ALB, Kalschne DL, Ferrão MAG, Fonseca AFA, Da Ferrao RG, Benassi MT. Diterpenes in Coffea canephora. J Food Composition Anal, 2016; 52:52-7.

Mussatto SI, Machado EMS, Martins S, Teixeira JA. Production, composition, and application of coffee and its industrial residues. Food Bioprocess Technol, 2011; 4:661-72.

Nam MW, Zhao J, Lee MS, Jeong JH, Lee J. Enhanced extraction of bioactive natural products using tailor-made deep eutectic solvents: application to flavonoid extraction from Flos sophorae. Green Chem, 2015; 17:1718-27.

Navarra G, Moschetti M, Guarrasi V, Mangione MR, Militello V, Leone M. Simultaneous determination of caffeine and chlorogenic acids in green coffee by UV/Vis spectroscopy. J Chem, 2017; 2017:1-8.

Ong KW, Hsu A, Tan BKH. Anti-diabetic and anti-lipidemic effects of chlorogenic acid are mediated by AMPK activation. Biochem Pharmacol, 2013; 85:1341-51.
Shimoda H, Seki E, Aitani M. Inhibitory effect of green coffee bean extract on fat accumulation and body weight gain in mice. BMC Complement Altern Med, 2006; 6:9.

Vian M, Breil C, Vernes L, Chaabani E, Chemat. Green solvents for sample preparation in analytical chemistry. Curr Opin Green Sustain Chem, 2017; 5:44-8.

Wei ZF, Wang XQ, Peng X, Wang W, Zhao CJ, Zu YG, Fu YJ. Fast and green extraction and separation of main bioactive flavonoids from Radix Scutellariae. Indust Crops Prod, 2015a; 63:175-81.

Wei Z, Qi X, Li T, Luo M, Wang W, Zu Y, Fu Y. Application of natural deep eutectic solvents for extraction and determination of phenolics in Cajanus cajan leaves by ultra performance liquid chromatography. Separat Purificat Technol, 2015b; 149:237-44.

$\mathrm{Xu}$ JG, Hu QP, Liu Y. Antioxidant and DNA-protective activities of chlorogenic acid isomers. J Agr Food Chem, 2012; 60:11625-30.

Zhao BY, Xu P, Yang FX, Wu $\mathrm{H}$, Zong $\mathrm{MH}$, Lou WY Biocompatible deep eutectic solvents based on choline chloride: characterization and application to the extraction of rutin from Sophora japonica. ACS Sustain Chem Eng, 2015; 3:2746-55.

\section{How to cite this article:}

Yuniarti E, Saputri FC, Mun'im A. Application of the natural deep eutectic solvent choline chloride-sorbitol to extract chlorogenic acid and caffeine from green coffee beans (Coffea canephora). J Appl Pharm Sci, 2019; 9(03):082-090. 